\title{
Rheological and Thermal Behavior of High-Density Polyethylene (HDPE) at Different Temperatures
}

\author{
Cynthia D'Avila Carvalho Erbetta, Getúlio F. Manoel, Ana Paula Lelis Rodrigues Oliveira, \\ Maria Elisa Scarpelli Ribeiro e Silva, Roberto Fernando Souza Freitas, \\ Ricardo Geraldo Sousa* \\ Polymer Science and Technology Laboratory, Chemical Engineering Department, Engineering School, Federal \\ University of Minas Gerais, Belo Horizonte, Brazil \\ Email: sousarg@ufmg.br
}

Received 28 August 2014; revised 2 October 2014; accepted 19 October 2014

Copyright (C) 2014 by authors and Scientific Research Publishing Inc.

This work is licensed under the Creative Commons Attribution International License (CC BY).

http://creativecommons.org/licenses/by/4.0/

(c) (i) Open Access

\begin{abstract}
In the present work, rheological properties of HDPE samples were measured at temperatures of $150^{\circ} \mathrm{C}, 190^{\circ} \mathrm{C}$ and $230^{\circ} \mathrm{C}$. It was shown, by oscillatory tests, at low frequencies, that, for temperatures of $150^{\circ} \mathrm{C}$ and $190^{\circ} \mathrm{C}$, there was a predominance of the viscous behavior over the elastic one. At $230^{\circ} \mathrm{C}$, there was a predominance of the elastic contribution, and there was an increase of the molar mass compared with the ones obtained from the tests at $150^{\circ} \mathrm{C}$ and $190^{\circ} \mathrm{C}$. The results obtained from the temperature ramp oscillatory test showed that, up to around $248^{\circ} \mathrm{C}$, the viscous behavior prevailed, the opposite being observed at higher temperatures. $\mathrm{At} 230^{\circ} \mathrm{C}$ the sample showed significantly lower values of strain when compared with the ones observed at $150^{\circ} \mathrm{C}$ and $190^{\circ} \mathrm{C}$. Oxidative induction time (OIT), melting point and degree of crystallinity were determined by differential scanning calorimetry (DSC). The DSC results and the rheological measurements showed a completely different behavior for the HDPE samples at $230^{\circ} \mathrm{C}$ compared with the $150^{\circ} \mathrm{C}$ and the $190^{\circ} \mathrm{C}$ ones, suggesting that HDPE, at the temperature of $230^{\circ} \mathrm{C}$, underwent thermo-oxidative degradation with the initial predominance of crosslinking.
\end{abstract}

\section{Keywords}

HDPE, Rheology, Degradation, DSC, FTIR

${ }^{*}$ Corresponding author.

How to cite this paper: Erbetta, C.D.C., Manoel, G.F., Oliveira, A.P.L.R., e Silva, M.E.S.R., Freitas, R.F.S. and Sousa, R.G. (2014) Rheological and Thermal Behavior of High-Density Polyethylene (HDPE) at Different Temperatures. Materials Sciences and Applications, 5, 923-931. http://dx.doi.org/10.4236/msa.2014.513094 


\section{Introduction}

Polyethylene (PE) is one of the most versatile commercial polymers, with its semi-crystalline nature allowing processing in a broad temperature range. The crystalline phase of the polymer provides resistance, while the amorphous phase provides flexibility [1].

PE degradation may occur from the time of its production to the time of its final use [2]. During processing PE may undergo, mainly, thermal, mechanical and chemical degradation. When these processes occur simultaneously, it is called thermo-oxidative degradation. The main phenomena which may occur during the thermooxidative degradation of PE are chain scission (decrease of molar mass) and reticulation (increase of molar mass); both of them alter the rheological behavior and the properties of the polymer [3]. Several works in the literature have studied the degradation of PE. In some of them, the scission phenomenon seems to have prevailed, once there is a reduction in the molar mass. However, in others, reticulation may have prevailed due to the increase in molar mass [4] [5]. Degradation during processing may occur in greater or lesser intensity, depending on the quantity and quality of the stabilizers added during polymerization and the introduction of additives [5].

$\mathrm{PE}$ is classified as a viscoelastic material. Rheological analysis is a powerful tool and provides an idea as to the molecular architecture of the polymer [6]. The rheological characteristics of PE resin determine which processing techniques are applicable, and, therefore, the range of final products which may be generated from it [7]. The relationship between the structure and the rheological behavior is the key to the development of new materials [8] [9]. The flow properties of viscoelastic fluids depend on temperature, strain rate and observation time. Among the rheological properties, viscosity is one of the most commonly utilized parameters in the study of polymeric material behavior during processing, once the majority of transformation processes occur in shear flows. Measurements of the storage or elastic (G') and the loss or viscous (G”) moduli, at shear conditions, which are, respectively, related to the stored and to the dissipated energy during a cycle, are also largely utilized in polymer processing studies. The storage modulus depends on the rigidity of the macromolecules and their entanglement, whereas the loss modulus depends on the links which control the conformational changes of the chain segments and the displacement of one chain in relation to the other. The elastic and viscous behavior of these materials can be altered by the application of stress or shear rate, and by the temperature of the test. The study of the dependency of viscosity on temperature helps to clarify the flow process mechanism and to elucidate the structural relation of polymers and their behavior under deformation, aside from having a substantial effect on the material processability. It is essential to know the viscoelastic behavior of polymeric materials, not only as a way to achieve optimized processing conditions, but also in order to obtain valuable information about the flow mechanism and its effect on the morphology and final mechanical properties [10].

Due to the importance of HDPE and in order to contribute to the understanding of its behavior during processing, in this paper we report the study of the rheological and of the thermal behavior of a high density polyethylene sample, at three different temperatures.

\section{Materials and Methods}

The HPDE sample used in this study has an average molar mass $\left(\mathrm{M}_{\mathrm{w}}\right)$ of $125,000 \mathrm{~g} \cdot \mathrm{mol}^{-1}$, and was obtained from Sigma-Aldrich in granular form with basic pre-stabilization for processing. The samples were used as received. All experiments were carried out in duplicate.

For the present study, three test temperatures were selected: $150^{\circ} \mathrm{C}, 190^{\circ} \mathrm{C}$ and $230^{\circ} \mathrm{C}$. The lowest value was selected for being above the sample melting temperature and for being the lowest temperature usually used in the extrusion process of HDPE $\left(\mathrm{T}=150^{\circ} \mathrm{C}\right)$. The highest temperature, $230^{\circ} \mathrm{C}$, was chosen based on the preliminary tests by rheometry and DSC. In the rheometer, the sample was subjected to the temperature ramp test (oscillatory test), with heating from 140 to $260^{\circ} \mathrm{C}\left(10^{\circ} \mathrm{C} \cdot \mathrm{min}^{-1}\right)$, under a shear rate of $5 \%$ (linear viscoelasticity). Change in the rheological behavior of the sample was observed above approximately $230^{\circ} \mathrm{C}$. In the DSC, the sample was subjected to the oxidative induction time test $(\mathrm{OIT})$ at $230^{\circ} \mathrm{C}$, where the beginning of oxidation was observed in less than 2 minutes, under oxidative atmosphere. Thus, a temperature of $230^{\circ} \mathrm{C}$ was chosen in order to evaluate the HDPE behavior during a probable thermo-oxidative degradation. As for the $190^{\circ} \mathrm{C}$ temperature, this was chosen for being the middle temperature between $150^{\circ} \mathrm{C}$ and $230^{\circ} \mathrm{C}$.

The analyzed samples were prepared in the rheometer, obtained in disc form, $8 \mathrm{~mm}$ in diameter and $1 \mathrm{~mm}$ in thickness. At $230^{\circ} \mathrm{C}$, the preparation time was 1 minute, at $190^{\circ} \mathrm{C}, 2$ minutes, and, at $150^{\circ} \mathrm{C}, 3$ minutes. The samples were characterized by FTIR and by DSC. 


\subsection{Fourier Transform Infrared Spectroscopy Analysis (FTIR)}

The FTIR technique was applied with the main objective of identifying any alteration in the HDPE composition during sample preparation, seeking to avoid the interference of this step on the rheological results. For this reason, samples were analyzed by FTIR, as they were received, and then again after preparation in the rheometer (prior to the rheological tests). To support the discussion of the results obtained from the rheological tests, an FTIR analysis of some HDPE samples was also conducted, after the rheological experiments. The spectra, in the 4000 to $650 \mathrm{~cm}^{-1}$ range, were obtained in the FTIR spectrometer; model Nicolet 6700 from Thermo Fisher Scientific, in attenuated total reflectance (ATR), with 64 scans and $4 \mathrm{~cm}^{-1}$ resolution.

\subsection{Differential Scanning Calorimetry (DSC) Analysis}

A DSC analysis was conducted to determine the melting temperature $\left(T_{m}\right)$, the degree of crystallinity and the oxidative induction time (OIT). A Shimadzu DSC-60 model was used, with a sealed aluminum sample holder with perforated cap. Nitrogen was used as the carrier gas, at $30 \mathrm{~mL} \cdot \mathrm{min}^{-1}$. The mass of the analyzed samples varied from 4 to $6 \mathrm{mg}$. In order to determine $T_{m}$ and the degree of crystallinity, the samples were initially subjected to thermal treatment to erase the material thermal history. Next, the equipment was programmed for another run, starting from room temperature $\left( \pm 20^{\circ} \mathrm{C}\right)$ up to $200^{\circ} \mathrm{C}$, at $10^{\circ} \mathrm{C} \cdot \mathrm{min}^{-1}$. For the OIT tests, the samples were heated from room temperature up to test temperature $\left(150^{\circ} \mathrm{C}, 190^{\circ} \mathrm{C}\right.$ and $\left.230^{\circ} \mathrm{C}\right)$, at $10^{\circ} \mathrm{C} \cdot \mathrm{min}^{-1}$, utilizing initially nitrogen as the carrier gas, at $30 \mathrm{~mL} \cdot \mathrm{min}^{-1}$. At test temperature, an isotherm was maintained for 5 minutes in order to reach thermodynamic equilibrium and, following that, the exchange of the carrier gas from nitrogen to oxygen was conducted, maintaining the same flow and isotherm for a maximum 90 minutes. The OIT test was performed with the purpose of evaluating the thermal stability of the material at each temperature. With the OIT result, a time reference to which the sample can be subjected is obtained, without oxidative degradation. Or even the opposite, that is, a minimal time reference so that the oxidative degradation of the sample can occur.

\subsection{Rheometry Analysis}

The rheological tests were performed in a model AR-G2 rotational rheometer (TA Instruments), utilizing an 8 mm parallel plate geometry, with heating by an environmental test chamber (ETC) of the equipment. Environmental atmosphere was used in all rheological tests.

In order to determine the strain value to be applied to the rheological tests (linear viscoelasticity region), the G'and G" moduli curves were obtained as a function of a broad strain range $(0.01 \%$ to $100 \%)$, through a strain sweep test, maintaining the frequency constant at $1 \mathrm{~Hz}$. The frequency sweep test was performed in order to determine the average molar mass variation of the sample. The frequency range chosen was from 0.8 to $400 \mathrm{rad} \cdot \mathrm{s}^{-1}$ $(0.1$ to $64 \mathrm{~Hz})$, with a $5 \%$ strain, which lies within the linear viscoelasticity region.

In order to evaluate the viscoelastic behavior of the sample, when subjected to a continuous rise in temperature, an oscillatory temperature ramp test was performed. From this test, the variation of the G' and G' moduli was obtained, as a function of temperature, at a 5\% strain and at a $1 \mathrm{~Hz}$ frequency, with a heating rate of $10^{\circ} \mathrm{C} \cdot \mathrm{min}^{-1}$. The steady state flow test was performed to obtain the viscosity curve as a function of the shear rate, and to find, from it, the region of the 1st Newtonian plateau (the region where viscosity is kept constant for a certain stress interval or shear rate). In this test, the shear rate varied from $1 \times 10^{-5}$ to $10 \mathrm{~s}^{-1}$.

The creep test was, then, performed, with a $3000 \mathrm{~Pa}$ shear stress (outside of the Newtonian plateau). The objective of such test was to compare the elastic response of the sample at different temperatures. The study of the dependency of viscosity on temperature was carried out through a temperature ramp flow test $\left(140^{\circ} \mathrm{C}\right.$ to $\left.260^{\circ} \mathrm{C}\right)$, maintaining the shear rate constant at $1 \mathrm{~s}^{-1}$ (outside the Newtonian plateau).

The equilibrium time in the conditioning phase of each rheological test was standardized at 6 minutes for tests at $150^{\circ} \mathrm{C}$, and 3 minutes for tests at $190^{\circ} \mathrm{C}$ and $230^{\circ} \mathrm{C}$. For tests at $150^{\circ} \mathrm{C}$, a longer time was used in order to guarantee the complete fusion of the crystals, since the presence of residual crystals in the sample under analysis could affect the rheological test results. The rheological tests took 6.5 to $35.2 \mathrm{~min}$, at $150^{\circ} \mathrm{C}, 3.5$ to $32.2 \mathrm{~min}$, at $190^{\circ} \mathrm{C}$, and 3.5 to $33.8 \mathrm{~min}$, at $230^{\circ} \mathrm{C}$. The DSC analysis result (HDPE melting peak interval) was used as a reference to determine the equilibrium time. It is worth noting that the heating rate utilized in the DSC test was the same one utilized in the rheological temperature ramp tests $\left(10^{\circ} \mathrm{C} \cdot \mathrm{min}^{-1}\right)$, which had a test time of 18 minutes. 


\section{Results and Discuss}

From the FTIR analyses, it was possible to identify the PE characteristic bands, i.e., stretching between 2950 and $2850 \mathrm{~cm}^{-1}$; bending between 2950 and $2850 \mathrm{~cm}^{-1}$; rocking close to $700 \mathrm{~cm}^{-1}$ [11]. It was observed both in the spectrum of the HDPE sample, as received, as well as in the spectra of the specimens at all three temperatures, discrete bands between 965 and $946 \mathrm{~cm}^{-1}$, which indicate the presence of vinyl groups, as they absorb between 990 and $910 \mathrm{~cm}^{-1}$ [12]. The presence of carbonyl group $(\mathrm{C}=\mathrm{O})$ (band close to $1700 \mathrm{~cm}^{-1}$ ) was not observed in any of the spectra analyzed at this stage. Thus, the FTIR results indicated that the chemical structure of the sample was preserved.

For characterization of the HDPE sample, as received, the $T_{m}$, the degree of crystallinity and the value of HDPE's OIT by DSC were determined, and the results are presented in Table 1.

The values found for the melting temperature and for the degree of crystallinity are in accordance with the literature $\left(\mathrm{T}_{\mathrm{m}}=125^{\circ} \mathrm{C}-132^{\circ} \mathrm{C}\right.$ and crystallinity $\left.=55 \%-77 \%\right)[7]$.

For $150^{\circ} \mathrm{C}$ and $190^{\circ} \mathrm{C}$, the DSC curves did not present any exothermic event, what means that there was no oxidation of the samples at these temperatures, within the 90 minute interval and under oxidizing atmosphere. Therefore, the OIT values for these temperatures are over 90 minutes. Thus, for $150^{\circ} \mathrm{C}$ and $190^{\circ} \mathrm{C}$, the occurrence of thermo-oxidative degradation is unlikely during rheological tests, since the time of these tests was under 90 minutes. However, this degradation could occur for rheological tests at $230^{\circ} \mathrm{C}$, once, at this temperature, these tests took a time superior to the OIT value $(1.27 \mathrm{~min})$. The OIT results obtained by DSC corroborate the FTIR results, once, for the specimens prepared in a shorter time than the OIT, there were no indications of HDPE degradation in their spectra.

In the study carried out by Mesquita $(2010)$, at $210^{\circ} \mathrm{C}$, OIT values of 0.4 min were found for HDPE samples without anti-oxidant additive, and up to $11 \mathrm{~min}$ for HDPE samples containing a mixture of primary and secondary anti-oxidant additives [4].

Figure 1 shows the curves of the elastic (G') and of the viscous (G”) moduli as a function of strain (\%), for temperatures of $150^{\circ} \mathrm{C}, 190^{\circ} \mathrm{C}$ and $230^{\circ} \mathrm{C}$, obtained in the strain sweep test.

It can be observed from Figure 1, a discrete predominance of the viscous effect ( $\left.G^{\prime \prime}>G^{\prime}\right)$ in the curves at 150 and $190^{\circ} \mathrm{C}$ and the opposite at $230^{\circ} \mathrm{C}$, where the elastic effect ( $\left.\mathrm{G}^{\prime}>\mathrm{G}^{\prime \prime}\right)$ prevails. It was possible to determine, with the aid of the equipment software, the linear viscoelasticity region more suitable for the three temperatures: strain between $1 \%$ and $10 \%$.

The result of the frequency sweep test is presented in Figure 2, by the G' and G" curves as a function of the angular frequency $\left(\mathrm{rad} \cdot \mathrm{s}^{-1}\right)$, under $5 \%$ strain (linear viscoelasticity). In this figure, the predominance of the viscous effect over the elastic effect at $150^{\circ} \mathrm{C}$ and $190^{\circ} \mathrm{C}$ can be observed, when at a low angular frequency. Under the same conditions, the opposite occurs at $230^{\circ} \mathrm{C}$, where the elastic effect prevails. At a specific frequency $\left(\mathrm{w}_{\mathrm{c}}\right)$, there is a crossing between the $\mathrm{G}^{\prime}$ and $\mathrm{G}^{\prime}\left(\mathrm{G}_{\mathrm{c}}\right)$ curves, and from this point, there is an inversion on the behavior, the elastic effect prevailing over the viscous effect at temperatures of $150^{\circ} \mathrm{C}$ and $190^{\circ} \mathrm{C}$ and the opposite occurring at $230^{\circ} \mathrm{C}$.

According to Scuracchio and Bretas (2004), in a typical response of molten polymers, the predominance of the elastic behavior at high frequencies is observed, and the viscous effect is observed at lower frequencies [15]. The specimens at $150^{\circ} \mathrm{C}$ and $190^{\circ} \mathrm{C}$ presented similar behavior to that reported in the literature.

Table 2 shows data from the point of intersection between G' (w) and G" (w) curves for each temperature, also designated as critical point $\left(\mathrm{w}_{\mathrm{c}}, \mathrm{G}_{\mathrm{c}}\right)$, the values of the average molar mass $\left(\mathrm{M}_{\mathrm{w}}\right)$, calculated by the rheometry equipment software, and the results of HDPE creep-recovery test, at the three temperatures used in this work.

From the data presented in Table 2, results of the same order of magnitude for $\mathrm{G}_{\mathrm{c}}$ and $\mathrm{M}_{\mathrm{w}}$ were observed, but when these results are compared with the results obtained at $230^{\circ} \mathrm{C}$, it becomes clear that there was a significant increase in $\mathrm{G}_{\mathrm{c}}$ and $\mathrm{M}_{\mathrm{w}}$. Similarly to what was observed by Torres (2007) [16], with the temperature increase, the critical point shifted to higher frequencies. The increase in value of the average molar mass at $230^{\circ} \mathrm{C}$ may indicate the occurrence of HDPE reticulation during the test.

Table 1. Results of DSC analyses for HDPE sample as received.

\begin{tabular}{|c|c|c|c|c|c|}
\hline $\mathbf{T}_{\mathrm{m}}\left({ }^{\circ} \mathbf{C}\right)$ & $\Delta \mathbf{H}_{\mathrm{m}}\left(\mathrm{J} \cdot \mathrm{g}^{-1}\right)$ & Crystallinity (\%) & OIT $150^{\circ} \mathrm{C}$ (min.) & OIT $190^{\circ} \mathrm{C}$ (min.) & OIT $230^{\circ} \mathrm{C}$ (min.) \\
\hline 131 & 170.85 & 59 & $>90$ & $>90$ & 1.27 \\
\hline
\end{tabular}




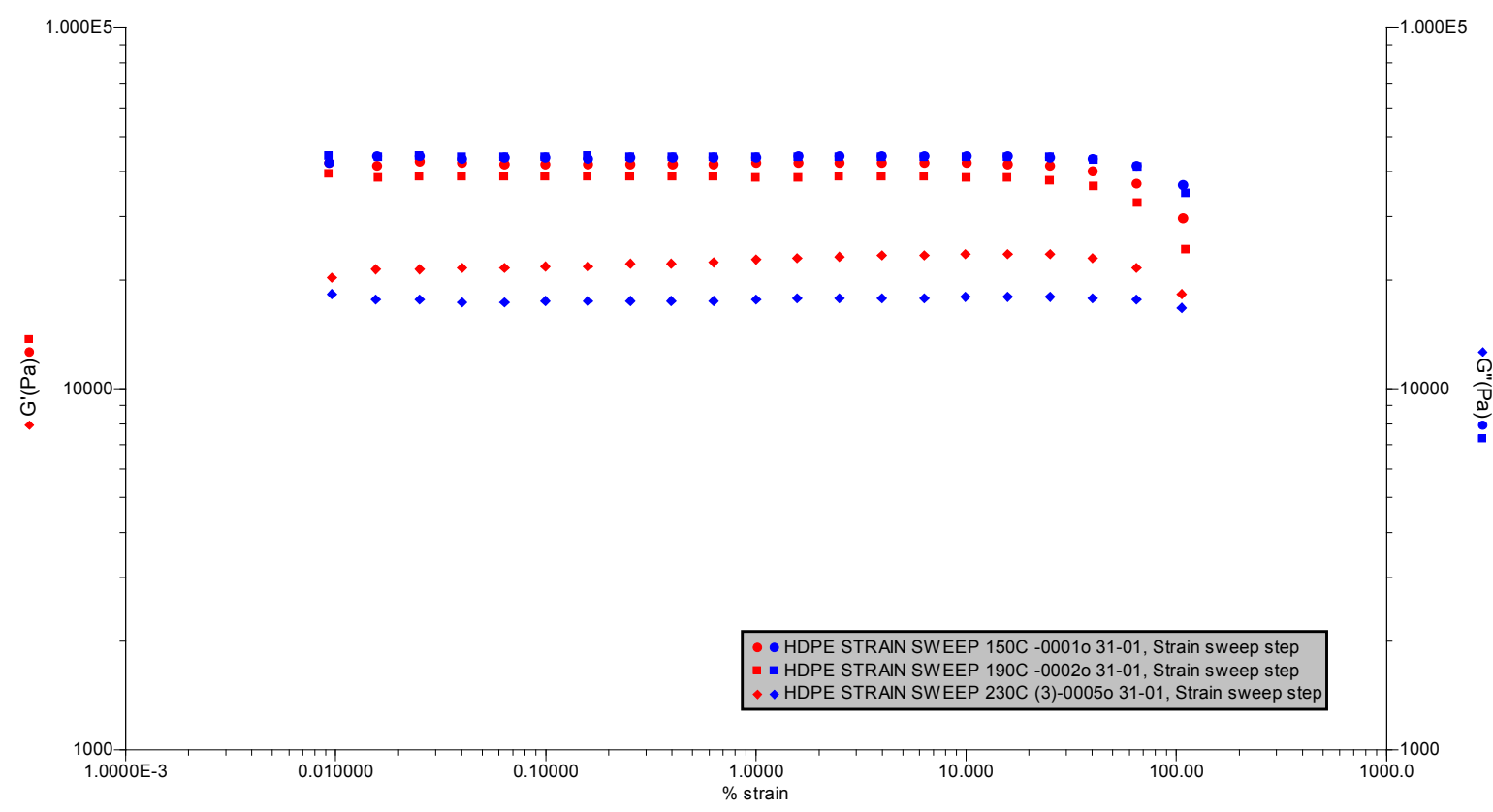

Figure 1. Strain sweep test curves for HDPE at $150^{\circ} \mathrm{C}(\bullet \bullet), 190^{\circ} \mathrm{C}(\square-\nabla)$ and $230^{\circ} \mathrm{C}(\bullet)$.

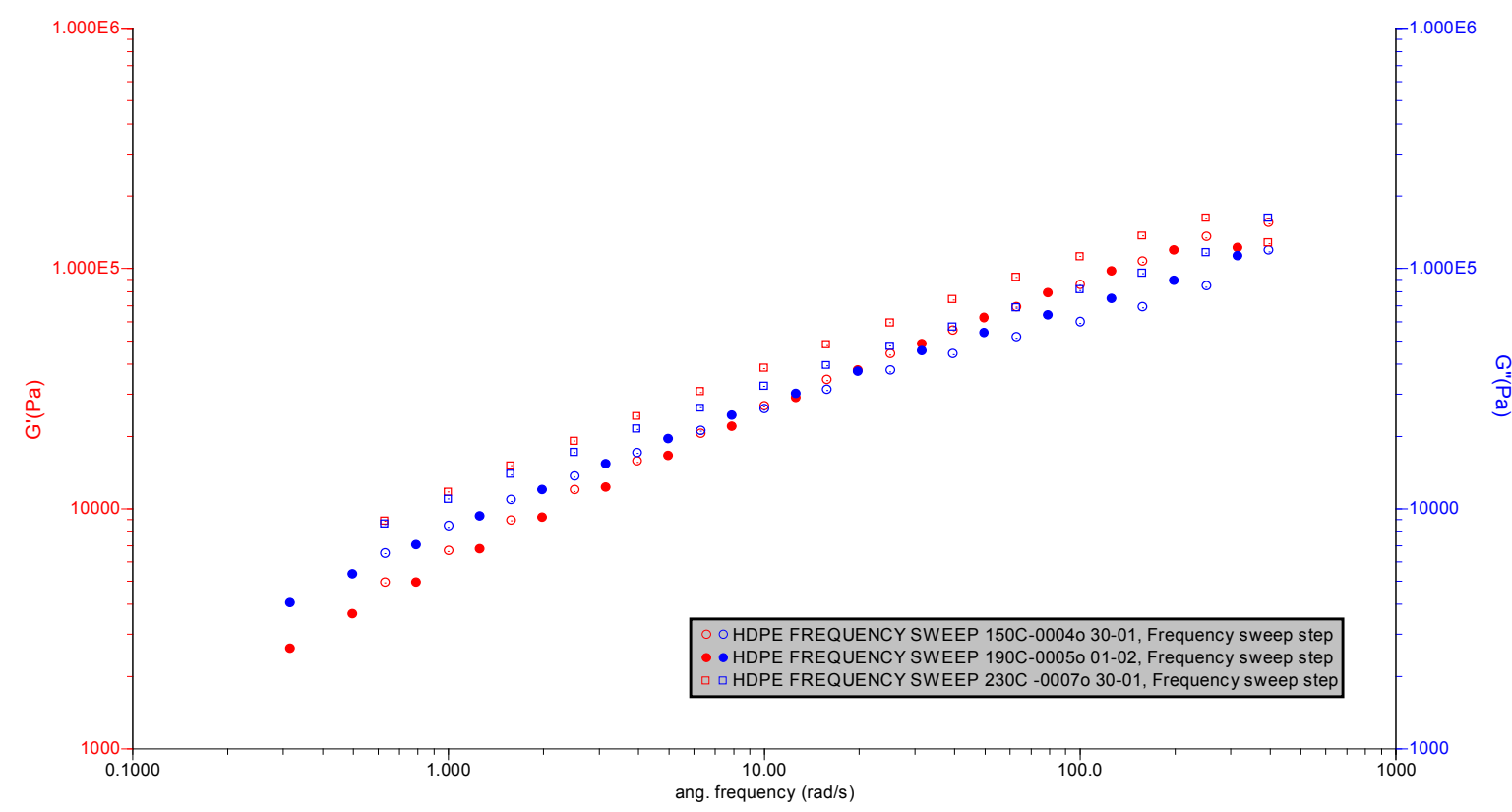

Figure 2. Curves of the HDPE frequency sweep test at $150^{\circ} \mathrm{C}(\bullet \bullet), 190^{\circ} \mathrm{C}(\bullet \bullet)$ and $230^{\circ} \mathrm{C}(\square \square)$.

Table 2. $\mathrm{G}_{\mathrm{c}}, \mathrm{w}_{\mathrm{c}}$ and $\mathrm{M}_{\mathrm{w}}$ data obtained in the frequency sweep test and results from the HDPE creep-recovery test at different temperatures.

\begin{tabular}{cccc}
\hline Temperature $\left({ }^{\circ} \mathbf{C}\right)$ & $\mathbf{1 5 0}$ & $\mathbf{1 9 0}$ & $\mathbf{2 3 0}$ \\
\hline $\mathbf{G}_{\mathbf{c}}(\mathbf{P a})$ & $2.292 \times 10^{4}$ & $3.539 \times 10^{4}$ & $1.403 \times 10^{5}$ \\
$\mathbf{w}_{\mathbf{c}}\left(\mathbf{r a d} \cdot \mathbf{s}^{-1}\right)$ & 7.68 & 18.10 & 327.60 \\
$\mathbf{M}_{\mathbf{w}}\left(\mathbf{g} \cdot \mathbf{m o l}^{-1}\right)$ & $9.457 \times 10^{5}$ & $9.851 \times 10^{5}$ & $7.139 \times 10^{6}$ \\
${\text { Initial strain }\left(\mathbf{S}_{\mathbf{i}}\right)}_{\text {Final strain }\left(\mathbf{S}_{\mathbf{f}}\right)}$ & 6.2914 & 3.8111 & 0.8971 \\
Final recovery $\left(\mathbf{S}_{\mathbf{R}}\right)$ & 2.3010 & 1.4657 & 0.2144 \\
\hline
\end{tabular}


The rheological behavior of HDPE as a function of temperature was evaluated by the oscillatory temperature ramp test, within the linear viscoelasticity region where, up to a temperature close to $246^{\circ} \mathrm{C}$, there was a predominance of the viscous effect over the elastic one ( $\left.\mathrm{G}^{\prime}>\mathrm{G}^{\prime}\right)$, with an opposite effect close to $250^{\circ} \mathrm{C}$. In the temperature interval between $230^{\circ} \mathrm{C}$ and $238^{\circ} \mathrm{C}$, it is possible to observe a change in the slope of the $\mathrm{G}^{\prime}(\mathrm{T})$ curves, which represents an increase in the elastic contribution to the rheological behavior of the sample, attributed to a change in its structure, possibly by the increase of the molar mass (degradation by reticulation), making the polymer more elastic. Using the rheometry equipment software, the critical point values were obtained: $\mathrm{G}_{\mathrm{c}}$ of 3.840 $\times 10^{4} \mathrm{~Pa}$ and temperature of $248^{\circ} \mathrm{C}$.

A Newtonian plateau with a shear rate between $2.55 \times 10^{-4}$ and $4.0 \times 10^{-3} \mathrm{~s}^{-1}$ was observed in the curves obtained at $150^{\circ} \mathrm{C}$ and $190^{\circ} \mathrm{C}$, in the steady state flow test. At $230^{\circ} \mathrm{C}$, the absence of this plateau became evident, indicating that, for the interval of shear rate and temperature applied, the HDPE does not present Newtonian behavior. Furthermore, at this temperature, it was observed a viscosity increase (increased flow resistance) for shear rates up to $0.01 \mathrm{~s}^{-1}$, approximately. For shear rates above this value, the viscosity decreases drastically. According to Peacock (2000), the alteration in viscosity of the molten polymer, as a function of shear rate, reflects alterations in its entanglement [7]. The similarity between the viscosity curves at $150^{\circ} \mathrm{C}$ and $190^{\circ} \mathrm{C}$ was also noted. A similar behavior was observed in the strain sweep test at these two temperatures. From the frequency sweep test, it was found very close values for the molar mass of HDPE for the tests carried out at $150^{\circ} \mathrm{C}$ and $190^{\circ} \mathrm{C}$, which contributes to justify the similarity of the viscosity behavior of the sample at these temperatures.

In the creep test, the sample was subjected to a constant stress of $3000 \mathrm{~Pa}$ for 30 seconds and the strain was measured as a function of time. In the recovery step, after 300 seconds, elastic recovery of the sample was registered.

The values for recovery from deformation or elastic recovery $\left(\mathrm{S}_{\mathrm{R}}\right)$, presented in the last line of Table 2, were calculated by Equation (1) [16], where $S_{i}$ is the initial deformation after removal of the stress and $S_{f}$ is the final deformation after 300 seconds (end of recovery).

$$
S_{R}=\frac{S_{i}-S_{f}}{S_{i}} \times 100
$$

From the results presented in Table 2, it was found very close values for the elastic recovery for the tests carried out at $150^{\circ} \mathrm{C}$ and $190^{\circ} \mathrm{C}\left(63 \%\right.$ and $62 \%$, respectively) and greater value for the one carried out at $230^{\circ} \mathrm{C}$ $(76 \%)$. It is noted that, at $230^{\circ} \mathrm{C}$, the sample presented the lesser deformation and the greater recovery, which may be related to the probable crosslinking of HDPE (greater resistance to deformation due to the effect of crosslinking). Such a result supports what was observed in the oscillatory tests at $230^{\circ} \mathrm{C}$, i.e., the prevailing elastic behavior and the increase in the average molar mass of the polymer. The fact that HDPE presents practically the same elastic recovery at $150^{\circ} \mathrm{C}$ and at $190^{\circ} \mathrm{C}$, may be justified considering the similarity of the viscosity behavior and also of the average molar mass, at these two temperatures.

It was observed from the viscosity as a function of temperature curves, obtained from the temperature ramp flow test, maintaining a shear rate at $1 \mathrm{~s}^{-1}$, a decrease in viscosity till a temperature close to $240^{\circ} \mathrm{C}$, point at which a change in the slope of the curve occurs, thus occurring a slight increase in viscosity. Such behavior corroborates the frequency sweep test results, once the increase in the polymer molar mass results in an increase in viscosity. At temperatures around $260^{\circ} \mathrm{C}$, a new change in slope of the viscosity curve is observed, followed by a small reduction of its value. Thus, the results of the temperature ramp flow tests indicate a change in the structure of the sample, which could be related to HDPE degradation with an initial predominance of crosslinking, and, thereafter, of chain scission (reduction in the viscosity at the end of the curve).

After the rheological experiments, some samples were analyzed by FTIR, in order to identify signs of polymer degradation. Figure 3 presents the FTIR spectrum of one of the samples after the steady state flow experiment at $230^{\circ} \mathrm{C}$ and, also, the spectrum of the specimen prepared at this temperature, for comparison. This rheological experiment, specifically, lasted 33.8 minutes.

The presence of new absorption bands characteristic of an oxidizing phenomenon can be observed from Figure 3 , which also reveals the presence of $\mathrm{C}-\mathrm{O}$ bonds between $1200-1100 \mathrm{~cm}^{-1}$ and carbonyl units $(\mathrm{C}=\mathrm{O})$ between $1800-1700 \mathrm{~cm}^{-1}$.

The presence of carbonyl was also detected in the FTIR spectrum after the temperature ramp flow test $\left(140^{\circ} \mathrm{C}\right.$ to $260^{\circ} \mathrm{C}$ ) (duration of test: $18 \mathrm{~min}$ ). The formation of carbonyl groups $(\mathrm{C}=\mathrm{O})$ may be related to the degradation 


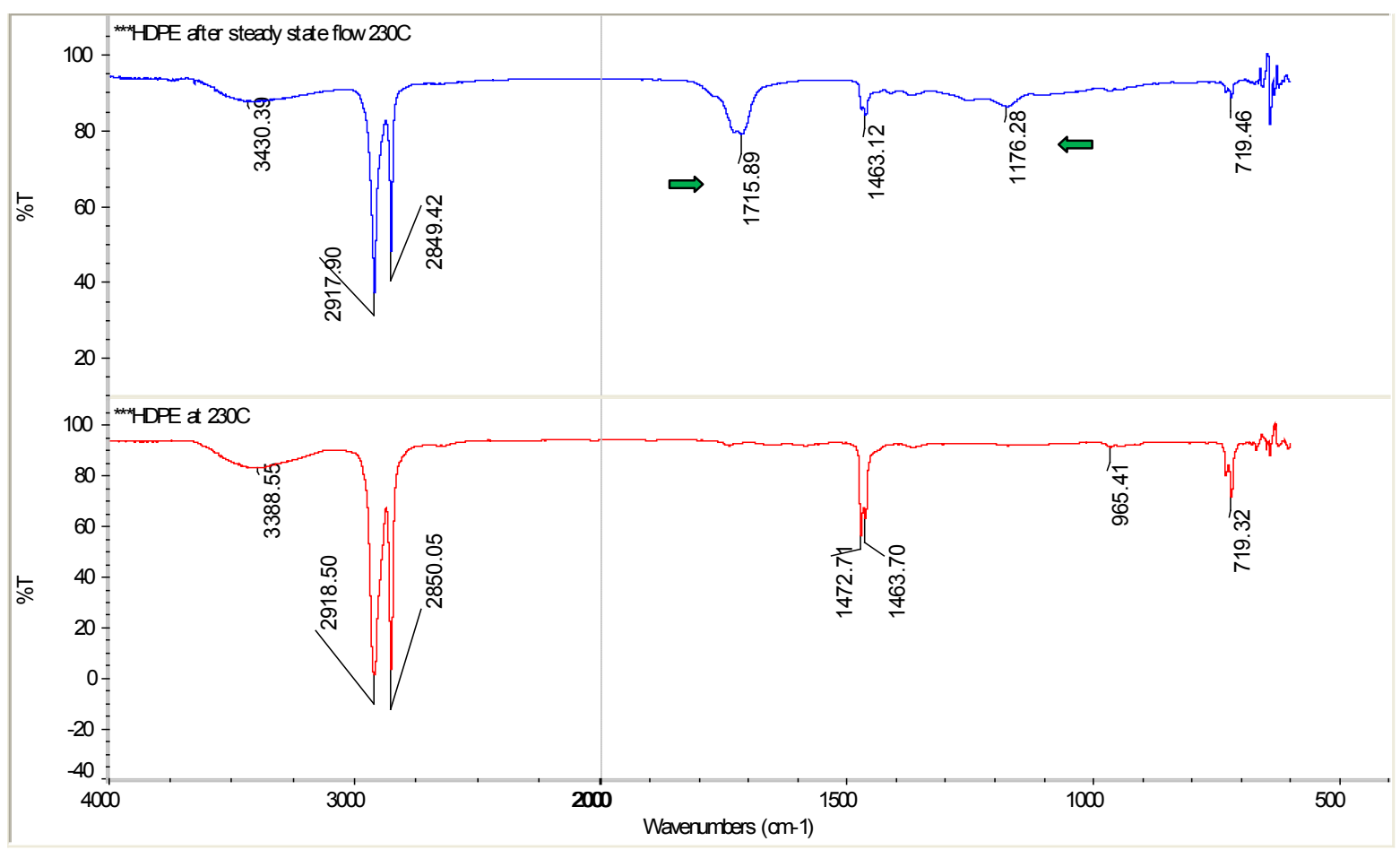

Figure 3. FTIR spectra for HDPE sample after the steady state flow test at $230^{\circ} \mathrm{C}$ and for the specimen prepared at a temperature of $230^{\circ} \mathrm{C}$.

of polyethylene by chain scission, more specifically, the $\beta$ scission of the peroxy radical (ROO*) or alkoxy $\left(\mathrm{RO}^{*}\right)$ [16]. This corroborates the result of the rheological temperature ramp test (flow test), where the reduction of HDPE viscosity was observed at the end of the experiment, which may be related to the degradation by chain scission (reduction in molar mass).

When comparing the FTIR spectra from the HDPE sample after the frequency sweep test (an analysis time of $4.9 \mathrm{~min}$ ) and from the specimen, both at the same temperature of $230^{\circ} \mathrm{C}$, the presence of carbonyl group is not detected in the spectrum of the sample after the test, neither in the spectrum of the specimen. However, it is worth noting that the characteristic band of vinyl groups present in the spectrum of the specimen $\left(965 \mathrm{~cm}^{-1}\right)$, was not detected in the HDPE spectrum after the rheological test. Moss and Zweifel (1989) verified the occurrence of crosslinking in HDPE accompanied by a reduction in the concentration of vinyl groups [17].

The results indicate that the HDPE sample, when subjected to a temperature of $230^{\circ} \mathrm{C}$, for a period greatly superior than that for the OIT, may undergo degradation by chain scission, once the presence of carbonyl is detected in the FTIR spectrum. However, it cannot be inferred that chain scission is the only degradation mechanism present, once there are indications of degradation by crosslinking during the rheological tests, considering that there was an increase in molar mass, determined in the frequency sweep test, and considering the absence of the characteristic band of vinyl groups in the FTIR spectra after the rheological tests. According to Azevedo and co-authors (2010) [18], when there are vinyl groups in the main chain, crosslinking reaction is favored, as also demonstrated in the study by Hoang and co-authors (2006) [19], whose conclusion was that the PE crosslinking reaction initiated at the vinyl insaturation points.

The FTIR analysis results, after the rheological tests, suggest that, at $150^{\circ} \mathrm{C}$ and $190^{\circ} \mathrm{C}$, the samples did not undergo degradation, as opposed to what was observed at $230^{\circ} \mathrm{C}$. The DSC results corroborate the FTIR results, once it was possible to observe in the OIT experiments that, at $150^{\circ} \mathrm{C}$ and $190^{\circ} \mathrm{C}$, the $\mathrm{HDPE}$ did not undergo oxidation when subjected to the oxidizing atmosphere for 90 minutes. Nevertheless, at $230^{\circ} \mathrm{C}$, the beginning of oxidation occurred at 1.27 minutes (OIT value), a time period inferior to that of the rheological tests.

\section{Conclusion}

The obtained results indicated that the samples of HDPE used in this study, when subjected to temperatures of 
$150^{\circ} \mathrm{C}$ and of $190^{\circ} \mathrm{C}$, showed practically the same characteristics (viscosity, molar mass, predominance of the viscous behavior at low shear rates and elastic recovery). At a temperature of $230^{\circ} \mathrm{C}$, when in an oxidizing atmosphere, the sample underwent thermo-oxidative degradation with initial predominance of crosslinking, considering that there was an increase in molar mass, which consequently led to an increase in viscosity, besides presenting greater elastic recovery. However, for a time period much longer than the OIT value, the degradation process of the HDPE sample was dominated by chain scission phenomenon, which could be inferred by the reduction in viscosity and the presence of carbonyl groups in the FTIR spectrum. As a practical application, the results obtained in this work suggest that the processing temperature for the HDPE studied must be less than $230^{\circ} \mathrm{C}$. For higher temperatures, in order to avoid thermo-oxidative degradation, the introduction of specific additives will be necessary.

\section{Acknowledgements}

The authors thank the Polymer Science and Technology Laboratory of Federal University of Minas Gerais, FAPEMIG, CEMIG, Petrobras, CNPq and CAPES for all support for this research.

\section{References}

[1] Cheng, J.J. (2008) Mechanical and Chemical Properties of High Density Polyethylene: Effects of Microstructure on Creep Characteristics. Doctoral Thesis, University of Waterloo, Canada.

[2] Parrondo, A., Allen, N.S., Edge, M., Liauw, C.M., Fontán, E. and Corrales, T. (2002) Additive Interactions in the Stabilization of Film Grade High-Density Polyethylene. Part I: Stabilization and Influence of Zinc Stearate during Melt Processing. Journal of Vinyl \& Additive Technology, 8, 75-89. http://dx.doi.org/10.1002/vnl.10349

[3] De Paoli, M.A. (2008) Degradação e Estabilização de Polímeros. Artliber Editora Ltda, São Paulo.

[4] Mesquita, F.A. (2010) Modification of High Density Polyethylene Properties after Different Extrusion Conditions. M.Sc. Dissertation, University of São Paulo, São Paulo.

[5] Mendes, L.A.A. (2006) Study of Mechanisms of Degradation of the Polyethylene in Primary Recycling. Doctoral Thesis, University of Minho, Braga.

[6] Ferry, J.D. (1980) Viscoelastic Properties of Polymers. Wiley, New York.

[7] Peacock, A.J. (2000) Handbook of Polyethylene-Structures, Properties and Applications. Marcel Dekker, New York.

[8] Understanding Rheology of Thermoplastic Polymers (TA Instruments) (2004) http://www.tainstruments.com/pdf/literature/AAN013_V_1_U_Thermoplast.pdf

[9] Erbetta, C.D.C., Silva, M.E.S.R., Freitas, R.F.S. and Sousa, R.G. (2013) Evaluation of Thermal, Chemical and Rheological Properties of High Density Polyethylene (HDPE) Additives with Pro-Degrading Agent, after Processing. Proceedings of the 12th Brazilian Congress of Polymers, Florianópolis, 22-26 September 2013, 1-4.

[10] Cruz, S.A., Farah, M., Zanin, M. and Bretas, R.E.S. (2008) Evaluation of Rheological Properties of Virgin HDPE/ Recycled HDPE Blends. Polímeros: Ciência e Tecnologia, 18, 144-151. http://dx.doi.org/10.1590/S0104-14282008000200012

[11] Guimarães, M.J.O.C., Coutinho, F.M.B., Rocha, M.C.G., Bretas, R.E.S. and Farah, M. (2003) Rheology of High Density Polyethylene Toughened with Elastomeric Polyethylene. Polimeros: Ciência e Tecnologia, 13, 135-140. http://dx.doi.org/10.1590/S0104-14282003000200013

[12] Snyder, R.G. (1980) Spectroscopic Methods-Methods in Experimental Physics. Vol. 16, Part A, Academic Press, New York.

[13] Pinheiro, L.A., Chinelatto, M.A. and Canevarolo, S.V. (2004) The Role of Chain Scission and Chain Branching in High Density Polyethylene during Thermo-Mechanical Degradation. Polymer Degradation and Stability, 86, 445-453. http://dx.doi.org/10.1016/j.polymdegradstab.2004.05.016

[14] Hinsken, H., Moss, S., Pauchet, J. and Zweifel, H. (1991) Degradation of Polyolefins during Melt Processing. Polymer Degradation and Stability, 34, 279-293. http://dx.doi.org/10.1016/0141-3910(91)90123-9

[15] Scuracchio, C.H, Bretas, R.E.S. and Isayev, A.I. (2004) Blends of PS with SBR Devulcanized by Ultrasound: Rheology and Morphology. Journal of Elastomers and Plastics, 36, 45-75. http://dx.doi.org/10.1177/0095244304039913

[16] Torres, A.A.U. (2007) Physicochemical Ageing of HDPE Pipes Assigned to the Transportation of Petroleum Derivatives. M.Sc. Dissertation, Catholic University of Rio de Janeiro, Rio de Janeiro.

[17] Moss, S. and Zweifel, H. (1989) Degradation and Stabilization of High Density Polyethylene during Multiple Extru- 
sions. Polymer Degradation and Stability, 25, 217-245. http://dx.doi.org/10.1016/S0141-3910(89)81009-2

[18] Azevedo, J.B., Chávez, M.A. and Rabello, M.S. (2010) The Effect of a Crosslinking Agent on the Morphology and Physical and Mechanical Properties of Polymer Foams Based on EVA and EPDM. Polímeros: Ciência e Tecnologia, 20, 407-414. http://dx.doi.org/10.1590/S0104-14282011005000002

[19] Hoàng, E.M., Allen, N.S., Liauw, C.M., Fontán, E. and Lafuente, P. (2006) The Thermo-Oxidative Degradation of Metallocene Polyethylenes: Part 2: Thermal Oxidation in the Melt State. Polymer Degradation and Stability, 91, 13631372. http://dx.doi.org/10.1016/j.polymdegradstab.2005.07.018 
Scientific Research Publishing (SCIRP) is one of the largest Open Access journal publishers. It is currently publishing more than 200 open access, online, peer-reviewed journals covering a wide range of academic disciplines. SCIRP serves the worldwide academic communities and contributes to the progress and application of science with its publication.

Other selected journals from SCIRP are listed as below. Submit your manuscript to us via either submit@scirp.org or Online Submission Portal.
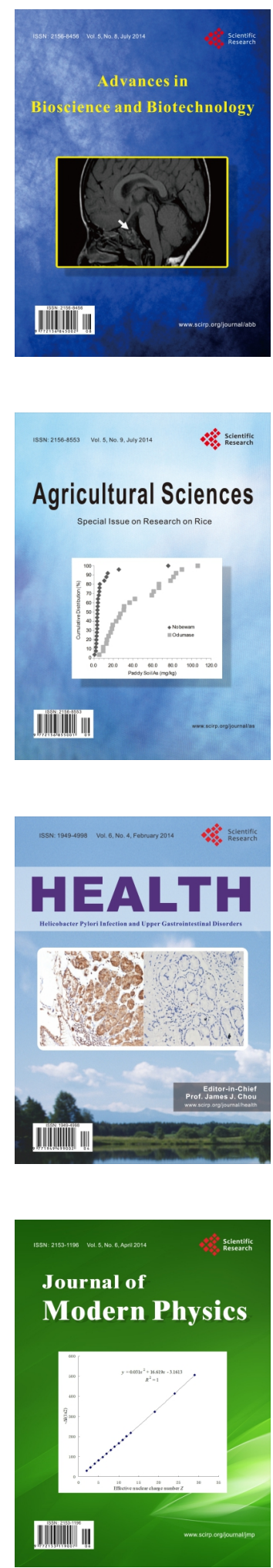
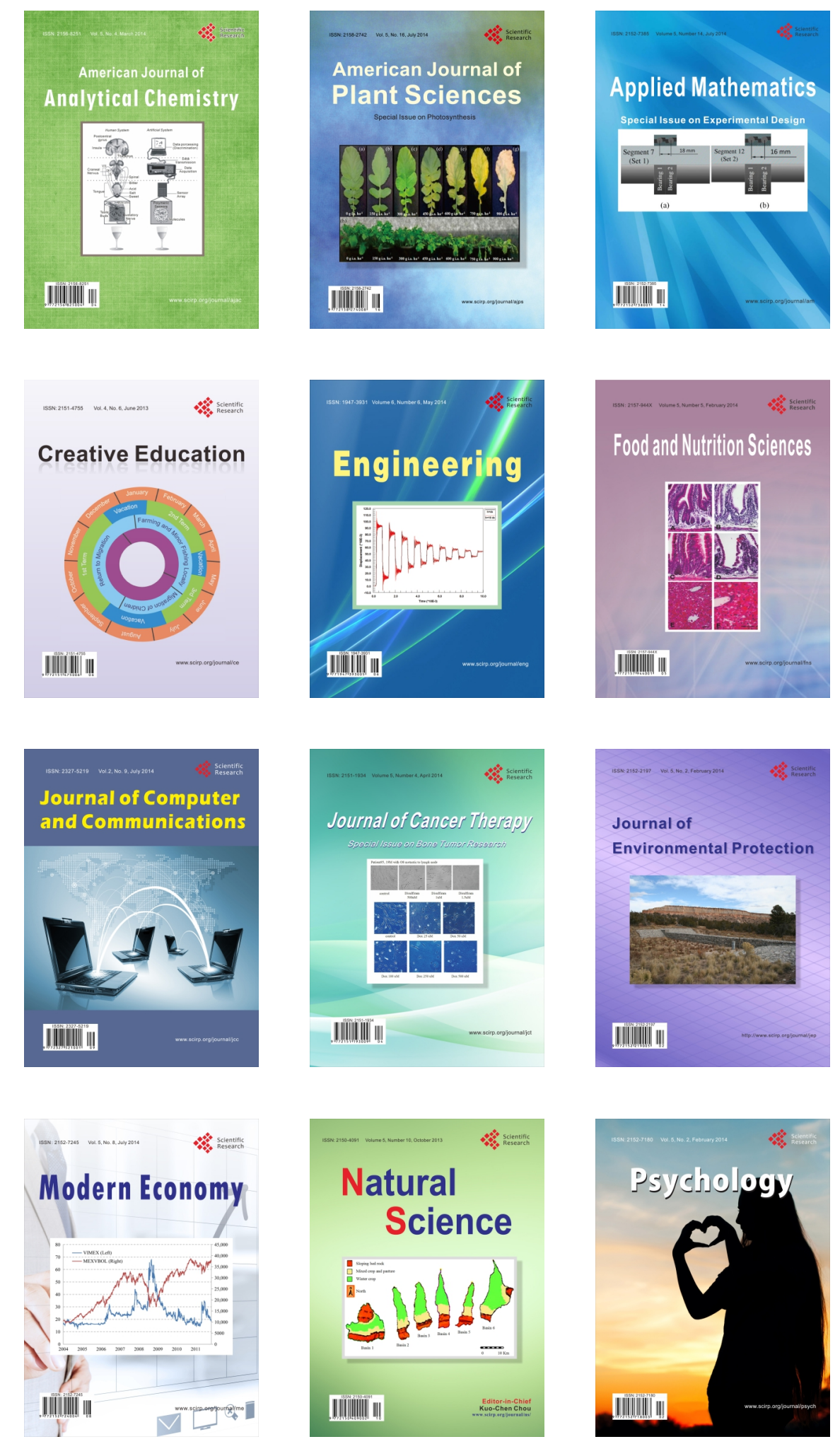